\title{
PSYCHIATRIC ASPECTS OF LIVER DISEASE
}

\author{
By Esther A. Davidson, M.B., M.R.C.P.(Edin), D.P.M., and \\ *W. H. J. Summerskili, M.A., D.M.(Oxon), M.R.C.P.(Lond.) \\ From the Department of Medicine, Postgraduate Medical School of London, Harvard Medical School and the Boston \\ City Hospital, Boston, Massachusetts
}

The Babylonians (circa 2000 B.c.) attributed powers of augury and divination to the liver, designating it by the term used also for ' soul' or 'mood' (Baumann, I93I), and clinical descriptions of an association between hepatic disease and mental disorders have been recorded since 'Hippocratic times. A patient with hepatitis ' developed a state like rabies; he could not be held, said things which could not be comprehended and barked like a dog ' (Morbis Internis), and the fatal illness of Hermocrates included a fluctuating delirium on the fifth day, followed by the appearance of jaundice on the sixth (Hippocrates, $460-370$ B.C.).

Hippocrates' concept of ' madness on account of bile' survived until recently in the term 'cholaemia,' but failed to explain mental changes in the non-jaundiced patient with liver disease. Galen (A.D. 13 I-200) implicated excess liver secretions as conducing to choleric and melancholic personalities and also contributed to a theory of hepatic function relevant to modern concepts of the liverbrain relationship. He considered that the liver prepared the blood from food in the stomach and that this blood spread into all parts of the body. Various psychiatric syndromes have now been recognized as incident to liver disease (Zillig, r947) and certain neuro-psychiatric conditions can be related to disorders of functional anatomy of the liver and portal system.

\section{The Concept of Portal-Systemic \\ Encephalopathy}

The significance of earlier observations that ammonium salts might provoke mental changes in patients with hepatic cirrhosis (Van Caulaert et al., 1932; Kirk, 1936) was stressed by the description of characteristic neuro-psychiatric findings in hepatic coma (Adams and Foley, 1953) and their reproduction by various nitrogenous substances (Phillips et al., i 952). The importance of deranged nitrogen metabolism in the genesis of hepatic coma

*Rockefeller Travelling Fellow of the Medical Research Council. is also evident from the observations of Sherlock and her colleagues (1954), who reported the characteristic syndrome occurring spontaneously in patients with liver disease, either as an acute or chronic disorder, and responding to protein withdrawal.

The term 'portal-systemic encephalopathy.' (Sherlock et al., 1954) was introduced to describe the neuro-psychiatric syndrome of which hepatic coma is the ultimate and most severe manifestation. It is based on clinical and biochemical investigations which relate the onset of neuro-psychiatric disorders of the same basic pattern to a combination of hepato-cellular disease of varied aetiology, shunting of portal blood to the systemic circulation and the presence of nitrogenous material in the intestines. Responsible factors vary in each patient, the route of toxic nitrogenous substances from the intestines to the brain being through a diseased liver, through portal collateral channels or by both routes (Fig. I).

Wagner-Jauregg ( 1896 ) launched the theory of

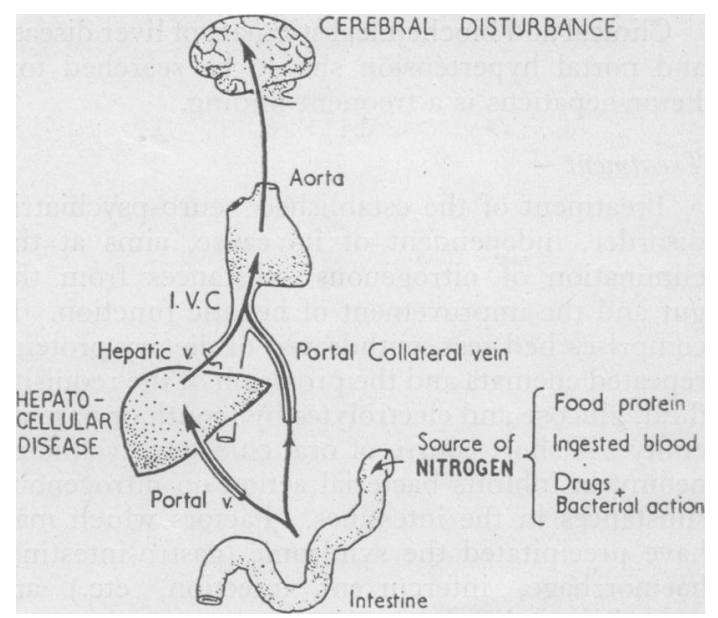

Fig. I-The mechanism of portal-systemic encephalopathy.

From Sherlock, et al., Lancet, ii, 453 (1954). 
intestinal auto-intoxication in mental disease and it was related to liver disease by Quastel (I93I), who believed that toxic amines resulting from bacterial action in the gut might produce confusional states because of impaired hepatic function. The nature of the substance producing portalsystemic encephalopathy and its effect on cerebral metabolism remain to be demonstrated, but much current investigation is directed towards the possibility that ammonia may be incriminated.

\section{Clinical Features}

The neuro-psychiatric disorder consists in an organic reaction associated with neurological disturbance. The psychiatric features vary in acuteness and therefore in symptomatology, depending on the nature and intensity of aetiological and precipitating factors, and its rate of progress to the onset of hepatic coma may vary from hours to years. The associated neurological and E.E.G. findings are of importance as confirmation of the significance of the mental changes.

In mild cases there may be no objective neurological findings. A coarse 'flapping' tremor on sustained posture of the limbs is the most characteristic feature, but tremor is not infrequently atypical. Additional disorder of the motor system includes increased muscle tone and tendon reflexes, often with ankle clonus and normal plantar responses, but, like other signs, these may be variable or absent. The facies is often devoid of expression, except when broken by fatuous grimaces, speech becomes slow and slurred, and sialorrhoea develops in more chronic cases. The E.E.G. changes were well described by Adams and Foley (1953) and are based on the presence of bilaterally synchronous, symmetrical, high-voltage, slow waves in the theta and delta ranges.

Clinical and biochemical stigmata of liver disease and portal hypertension should be searched for. Fetor hepaticus is a frequent finding.

\section{Treatment}

Treatment of the established neuro-psychiatric disorder, independent of its cause, aims at the elimination of nitrogenous substances from the gut and the improvement of hepatic function. It comprises bed rest, withdrawal of dietary protein, repeated enemata and the provision of the requisite fluid, glucose and electrolytes by mouth or parenterally. A short course of oral chlortetracycline or neomycin inhibits bacterial action on nitrogenous substances in the intestines. Factors which may have precipitated the syndrome (gastro-intestinal haemorrhage, intercurrent infection, etc.) are treated immediately.

Sedation of the noisy, violent patient presents problems, as most sedatives in common use, par- ticularly opiates, barbiturates and paraldehydêक have been incriminated as precipitants of hepatiô coma in patients with liver disease. Chlorpro 3 mazine may be of benefit; although it occasionall causes jaundice, there is no evidence that patients with liver disease are particularly susceptible. I $\vec{f}$ any case, the drug of choice should be exhibite of in small doses and withdrawn as soon as possible

Psychiatric Disorders Complicating Viru证 Hepatitis

Acute Liver Failure

In the fulminant form of the disease the psy $\vec{O}$ chiatric syndrome is an acute organic reaction with delirium (disorientation and visual hallusw cinosis) and clouding of consciousness rapidl progressing to coma within hours or days. Psy chiatric abnormalities may precede other clinicia ti features of the disease and jaundice may be late it appearing. This sequence of events can lead tô difficulties in diagnosis and the patient may b admitted to a mental hospital or observation wardpo

There is little to add to the Hippocratic descripe tion that these patients ' are vociferous and vicious and do not keep quiet.' Nightmares, headache and dizziness are inaugural, non-specific symp toms, but even before complaints are forthcoming the patient may show episodes of anti-social behaviour or character disturbance.

A 49-year-old deaf-mute, epileptic and psychog pathic, behaved with sudden unpreceder violence on a return visit to a mental hospita There was no overt confusion and no amnesia foo the episodes which were repeated following ad mission. On the fifth day he was febrile, vomite and passed rapidly into coma on the seventh da and died on the ninth. Jaundice appeared tero minally. Post-mortem examination confirmed the diagnosis of acute virus hepatitis.

Unco-operative behaviour often continues while consciousness is clouded. The delirium is of the noisy, restless variety and attacks of screaming occur spontaneously or may be induced by the slightest stimulus. Violent behaviour may not bis prominent in adults, but is common in childre (Spence and Ogilvie, 1927).

An II-year-old girl in the fourth week of hepatitis developed fever, anorexia, vomiting an $\frac{}{4}$ increasing jaundice and lapsed into coma, respond ing only to noxious stimuli with all the manifestao tions of extreme rage. Attacks of screamings occurred every few minutes and penetrated beyond्छ the hospital confines. Deliberately obstructive behaviour preceded the onset of coma and during lighter phases she screamed at her attendants to ' get out.'

The neurological features are the same as those found in portal-systemic encephalopathy from 
other causes. Diagnosis may be suggested, even in the absence of jaundice, by the clinical features, which include fetor hepaticus, a palpable spleen and diminishing liver dullness.

Prognosis in fulminating hepatitis is poor, but may be improved by appropriate treatment. Complete recovery of liver function is the rule in those surviving the attack.

\section{Depression}

Invasion by certain organisms, particularly the viruses of infective hepatitis and influenza, appears to be associated with the development of depressive states (Mayer-Gross et al., 1954). Depression occurs in the prodromal phase, during icterus or may continue as a distressing symptom after more objective evidence of the disease has disappeared (Findlay and Martin, 1943). Certain authors (Lichtman, 1953; Ford, 1943) stress that some degree of mental depression occurs commonly in the pre-icteric phase, usually disappearing with the onset of jaundice. Liebowitz and Gorman (1952) describe a psychotic reaction developing in the sixth week of severe infective hepatitis in a man of 30 years. Depression, with conviction of impending death and suicidal threats, was followed by sensorial clouding, defective memory, negative behaviour, silent staring, nocturnal insomnia, slow speech and agitated movements of the limbs. The authors stress the importance of categorizing each case according to whether the mental illness is coincidental, reactive or dependent on infective hepatitis.

Depression and incipient portal-systemic encephalopathy may closely simulate each other in symptomatology. The common features are the reduced psycho-motor activity, the fixed facial expression and nocturnal insomnia. Anorexia is as prominent in infective hepatitis as in depression and mood changes of a depressive kind may complicate the cerebro-toxic state. Only by careful exclusion of the organic syndrome and its associated neurological features can a diagnosis of coincidental or reactive depression be made. The distinction is important, since the treatment and prognosis varies. Temporary withdrawal of protein from the diet may assist in distinguishing the two conditions. A history of a previous attack of depression does not necessarily favour a diagnosis of a coincidental or reactive depression.

\section{Post-Hepatitis Syndrome}

This psychiatric syndrome is found almost exclusively in nursing personnel and doctors or among Service patients warded together awaiting repatriation (Sherlock and Walshe, 1946). Complaints are of fatigue, weight loss, anorexia and abdominal discomfort. The feature of this syn- drome in the medical group is fear of chronic liver disease as a sequel to virus hepatitis. Anxiety and depression occur and the liver remains apparently enlarged with exaggerated tenderness due to much anxious palpation by the patient himself. Sherlock and Walshe found that undue mobility of the liver and spleen through deep diaphragmatic respiration could make the normal organs palpable. Symptoms can be induced or aggravated by the medical attendant uncertain of the development of cirrhosis following infective hepatitis, as the return to normal values of flocculation tests of liver function is often delayed and follows clinical recovery. Iatrogenic conditioning of this syndrome may be avoided by eliminating unnecessary palpation and venepuncture in medical personnel convalescent from infective hepatitis.

In Service personnel the benefits of speedy repatriation and eligibility for pension awaited patients with chronic liver disease, so that the factors of gain through illness may have, consciously or unconsciously, determined the perpetuation of symptoms.

Treatment of the established syndrome is by reassurance following diagnostic liver biopsy; in the great majority of cases no evidence of cirrhosis is found.

\section{Psychiatric Disorders Complicating Hepatic Cirrhosis}

\section{The Acute Organic Reaction}

The features of the acute organic reaction may arise de novo in the patient with cirrhosis or, less commonly, they may occur as episodes punctuating a chronic state. The hallmark of the acute organic reaction is delirium characterized by clouding of consciousness, disorientation and visual hallucinosis. In the cirrhotic patient the sudden appearance of this syndrome associated with increasing neurological disorder demands investigation of its cause and treatment based on the concept of portal-systemic encephalopathy. The factors of liver cell function, portal-systemic venous shunting and nitrogen content of the gut must be assessed individually and in relation to each other. Acute deterioration in liver cell function may occur through haemorrhage, shock, deprivation of blood supply or from the action of drugs, poisons, anaesthetics or alcohol. Portal-systemic shunting of blood may become maximal from thrombosis of the portal vein, the construction of a surgical portacaval anastomosis or through liver cell failure. Paracentesis abdominis with resulting decrease in intra-abdominal pressure may accelerate the blood flow through intra- or extra-hepatic portal-systemic shunts. Nitrogenous substances in the gut may be increased directly by protein feeding, gastrointestinal haemorrhage or treatment with am- 
monium salts or indirectly by bacterial action. The final result of all precipitating factors is an increase in the amount of toxic nitrogenous substances delivered to the brain and this is reflected usually in a rise in arterial ammonia levels.

Treatment of acute portal-systemic encephalopathy is, as already outlined, modified according to the precipitants found.

Rigid selection of patients for surgical portacaval anastomosis is made by their ability to withstand, without neuro-psychiatric deterioration or electroencephalographic change, a diet containing $120 \mathrm{~g}$. protein for Io days. The construction of an adequate minimal functioning shunt, together with protein withdrawal and sterilization of the gut over the period of operation, help to prevent neuropsychiatric complications which may otherwise occur in as many as 33 per cent. of patients, particularly in the elderly (Wooler, 1955).

Delirium and coma in cirrhotic patients is often attributable to cerebral intoxication by nitrogenous substances, but where the clinical picture is atypical other causes or additive factors must be sought. Such causes may include drug intoxications, febrile deliria from coincidental infections or from abscess formation in the surgical patient, or disturbance of cerebral function due to water intoxication or electrolyte imbalance. The threshold for delirium may be reduced in children or in patients with previous disease of the central nervous system. The particular problems associated with alcoholism are discussed later.

\section{The Chronic Organic Reaction with Acute Exacerbations}

In a small proportion of patients with liver disease the characteristic neuro-psychiatric and E.E.G. findings of hepatic coma present as a chronic disorder with periodic exacerbations (Summerskill et al., 1956). An extensive portalsystemic collateral circulation can be demonstrated by transplenic portal venography (Atkinson et al., 1955) and the syndrome may follow portalsystemic anastomosis operations (McDermott and Adams, 1954). Fluctuations in the condition are related to the nitrogenous content of the diet and diagnosis can be confirmed by noting the effect of a precipitant, such as ammonium chloride (ro $\mathrm{g}$. daily), or by demonstrating improvement on protein withdrawal.

Clinical and biochemical evidence of liver disease may be equivocal or absent and mental disorder dominates the clinical picture.

A 67-year-old housewife, admitted as a certified patient to a mental hospital, had for one year shown a lack of her usual reticence and modesty with a failing memory, faulty habits and a gluttonous appetite. She had no recollection of 'bad turns' during which she was confused and disorientate with incomprehensible speech and manifest diffo culty in dressing. She learned to retire to bed whe shaking hands and an unsteady gait announced the onset of another blank spell. Previous health had been good apart from a three-weeks episode of jaundice at the age of 30 . There was no history of alcoholism or malnutrition.

The diagnosis of cirrhosis with portal-system encephalopathy was suggested by the diminisher awareness, upward gazing with perseverated dys: phasic utterance and marked grimacing of the acute episode. It was supported by the findings fetor hepaticus, hepato-splenomegaly, flapping tremor and exaggerated tendor reflexes and cornt firmed by the demonstration of ' nitrogen ins tolerance' with typical E.E.G. changes. Occlusion of the portal vein with a collateral circulation through a large inferior mesenteric vein was demonstrated on venography.

An intake of $50 \mathrm{~g}$. protein daily was compatible with good mental health. On $60 \mathrm{~g}$. daily she was inert, garrulous and reminiscent with minor defects in organic mental functions and minimal neuro logical signs. $80 \mathrm{~g}$. protein daily reproduced the acute episode with rapid advancement to coma. $\frac{?}{0}$

Intelligent co-operation in the management of her own diet allowed this patient to resume het normal life and activities. When her family, ofru convinced of her recovery, refused to accept she took up new responsibilities as housekeepefto a relative, a position she has discharged efficient for over one year.

The clinical psychiatric picture conforms with that of any chronic organic reaction in the featur of personality change, intellectual deterioration and lability of mood, and with any chronic intoxication in its fluctuating character. Although intermittent character changes occur (such as childishnese, irritability, loss of concern for family), many patients present in remission similar personalit features. They are co-operative, pleasant people with an ease in social relationships and frequent a jocular, euphoric mood. Emotional lability is les. frequently observed than persisting alterations i mood.

Intellectual deterioration varies from slight $\mathrm{im}_{\frac{5}{5}}$ pairment of organic mental functions to gross corn. fusion and daily fluctuations may be observe Focal defects, appearing in a setting of clear cor? sciousness, relate to disturbances in visual-spatide gnosis and are most easily elicited in the motof sphere as constructional apraxia, shown by ino ability to reproduce simple designs with blocs or matches (Fig. 2a). Symptoms of this defect afe manifest in various difficulties. Writing is typicalle oblivious of rulings (Fig. 2b); dressing presents problems to some patients, one cannot fill up $\overline{\frac{9}{9}}$ 

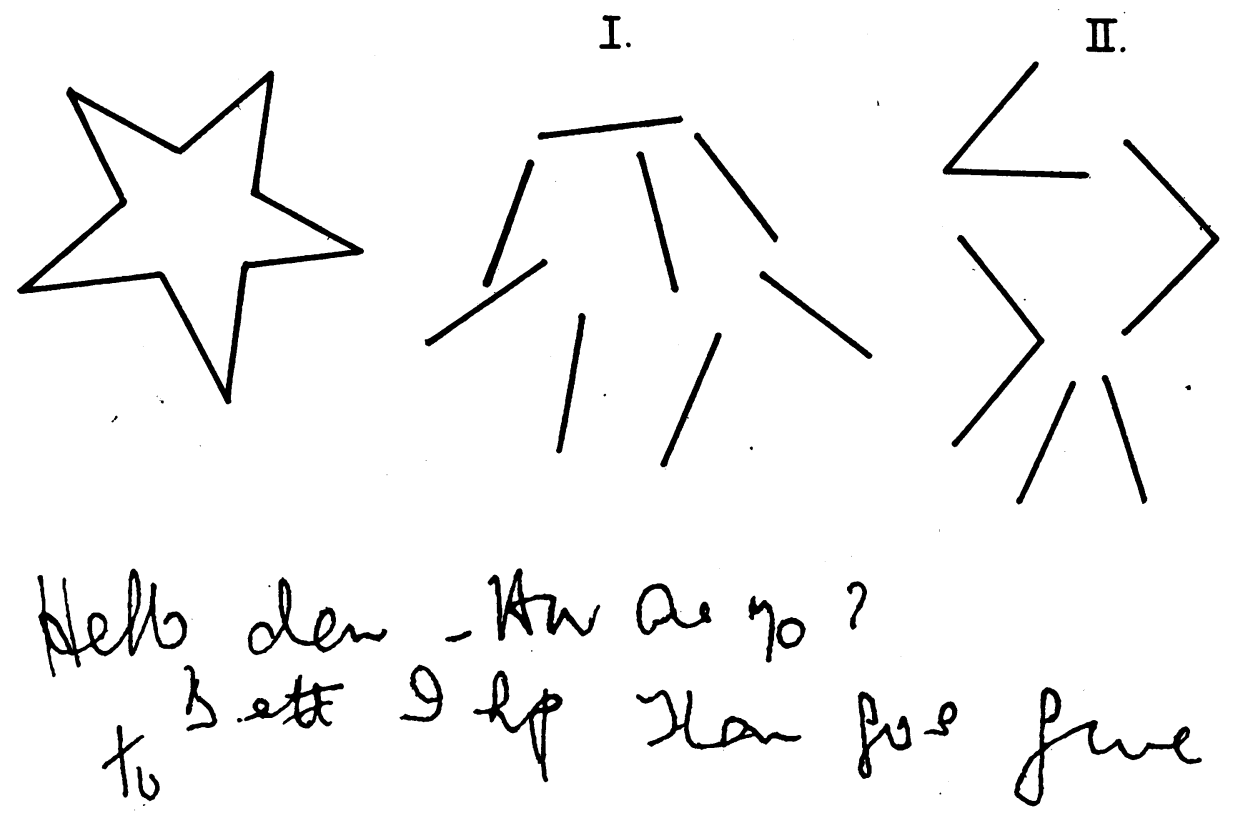

FIG. 2.-Focal disorders in chronic portal systemic encephalopathy elicited in patients with full consciousness and minimal intellectual defect, in the absence of gross tremor or visual disorder.

(a) Constructional apraxia.

(b) Writing difficulty. 'Hello dear. How are you ? Better I hope. That goes for me too.'

cheque, another has difficulty in following lines of print, some lose themselves in familiar surroundings (sometimes neglecting the left half of space). Failure to distinguish objects of similar size, shape, function or position leads to the frequently observed symptom of micturating and defaecating in inappropriate places. Insight into such anomalies of behaviour is frequently preserved. Benhamou et al. (1955) tell of a patient micturating in a corner of the room who murmured, 'C'est dégoutant.' One of our patients described her dressing and undressing difficulty as the funniest experience of her life.

'Confusion' of this type is usually episodic, since the condition is never static. It may be a prelude to ' coma' in which clouding of consciousness exists with language disorder characterized by dysphasia with perseveration and loss of propositional speech.

Consciousness and sleep are disturbed in various ways. The acute disturbances which punctuate the course of the chronic disorder are expressed in the clouded sensorium of delirium advancing to coma, the episodes being covered by amnesia. Less acute disturbances are shown by drowsiness and confusion, while in the chronic state diurnal somnolence from which the patient is easily roused presents the most common pattern of disturbance. Other manifestations which have been observed are nocturnal insomnia, narcolepsy, fugues and twilight states.

Disturbances of sensation include blurred or double vision, loss of visual acuity, simple visual hallucinations (lights and stars), paraesthesias and numbness. Perceptual anomalies also occur (macropsia, distortion and prolongation of the image, synaesthesia).

Psychomotor disturbance is shown in the disinclination for activity and poverty of spontaneous movement, which are almost constant. Fixity of expression, staring, stupor and catatonic posturing are observed. Forced activity has been observed to lead to deterioration and neurasthenic syndromes sometimes complicate the chronic state.

Neurological signs usually develop and regress in association with the psychiatric manifestations, but may be dissociated.

Psychiatric 'functional' reactions complicate the clinical picture in about half the patients and may mislead by reason of their lack of relationship to the intensity of the organic reaction or the neurological signs. Usually transient, they comprise mainly manic-depressive and paranoid reactions and can be related to the previous personality type. Their occurrence as incipient manifestations may not be regarded as symptomatic of portal-systemic encephalopathy. We know of two 
patients who failed to show any good response to electroplexy.

Treatment is modified to include long-term dietary restriction of protein within the limits of the individual nitrogen tolerance (usually 20 to $60 \mathrm{~g}$. protein daily). Education of the patient and his relatives in the management of the disorder and in the recognition of symptoms of impending deterioration is important. Prognosis depends on the extent and activity of hepato-cellular disease, the incidence of complications, such as gastrointestinal haemorrhage, and the intelligence with which the patient applies himself to the regime of treatment.

\section{Liver Disease, Alcoholism and Malnutrition}

In the 'civilized' world the commonest type of chronic liver disease is cirrhosis occurring in individuals habituated to the intemperate use of alcohol. Associated nutritional deficiency is woven into the clinical pattern, but the inter-relationship of cirrhosis, alcoholism and malnutrition remains unsettled. Cirrhosis of the alcoholic is often associated with parotid enlargement, Dupuytren's contracture, peripheral neuritis and other nutritional stigmata, an increased incidence of peptic ulcer and pancreatitis and macrocytic anaemia. Relapses sometimes occur with very deep jaundice more suggestive of acute hepatitis. Neuropsychiatric disorder in such patients may be attributable to portal-systemic encephalopathy, the syndromes associated with alcoholism and malnutrition or to combinations of these factors.

The effects of alcohol on the nervous system are well reviewed by Victor and Adams (1953) and their classification has been employed. Acute inebriation accounted for 59 per cent. of the comatose admitted in a year to the Boston City Hospital (Solomon and Aring, 1934); careful diagnosis by exclusion is necessary in the patient with cirrhosis. Delirium tremens, the most severe and dangerous of the tremulous - hallucinatory - epileptic - delirious conditions associated with alcohol withdrawal, may follow a drinking ' spree' or appear during unrelated illness in the 'steady' drinker. Continuous motor and autonomic over-activity, total insomnia, terrifying hallucinations and a finer, more rapid tremor differentiate this syndrome from the delirium of impending hepatic coma. Alcoholic tremulousness (the 'shakes' or 'jitters') occurs more frequently. The patient is flushed, agitated, inattentive and perfunctory in his replies. Tremor, absent at rest, becomes coarse and irregular on activity. Profound anorexia, often with retching and vomiting, is common. Treatment, as for delirium tremens, is based on sedation by chlorpromazine or reserpine and the prognosis is relatively good. Atypical states include periods of quiet confusion and bizarre behaviour on cessation of drinking and Kraepelin's acute auditory hallucinosis, in which behaviour dictated by 'voices' occurs in a setting of clear consciousness and full $\stackrel{\complement}{\llcorner}$ orientation. Alcoholic epilepsy (' rum fits') may'. complicate delirium tremens.

Alcoholic tremulousness or delirium tremenso may arise during decompensation of liver disease or hepatic coma, thus causing real diagnostic $\frac{\bar{c}}{\bar{\sigma}}$ difficulty.

A 34-year-old fireman, drinking heavily until the day of admission, entered hospital following $a_{-}^{\infty}$ gastro-intestinal haemorrhage. He showed stig-. mata of liver disease and was drowsy and confused $\vec{\omega}$ with limb rigidity and a flapping tremor. Haemor- $\omega$ rhage was arrested and after three days' treatmento with protein withdrawal and glutamic acid there 3 . was no residual neuro-psychiatric abnormality. The next day he became noisy, violent and con- $-\omega$ fused with a coarse tremor, in the absence of recurrent bleeding or deterioration in liver function. $\frac{+}{\infty}$ Chlorpromazine, I2.5 mg.b.d., was followed by av return to normal within 48 hours.

The 'steady' drinker commonly has a poornutritional background from which no specific요 deficiency can be isolated and clinical findingsô usually indicate more than one disease entity. Wernicke's encephalopathy is of fairly acute onset. Varying delirium with drowsiness is associatede with ocular disturbance (nystagmus and paresis) and ataxia. The condition responds well to thi mine treatment, but the amnesia for recent events and confabulation of Korsakow's syndrome mayō persist and are frequently associated with peri-气ू pheral neuritis. The diagnosis may be difficult, $\stackrel{\mathbb{Q}}{\varrho}$ especially when the condition arises in the course $\vec{\circ}$ of liver disease or hepatic coma.

A 44-year-old male alcoholic with cirrhosis was? admitted to hospital deeply jaundiced and in hepatic coma. He had been drinking until ad-o mission, but had been drowsy and unco-operative in the previous three days. A year earlier he hado been treated for beri-beri heart disease. On protein. withdrawal he regained consciousness the followingo day and three days later he was alert, orientated and free from tremor and other residual neuro-윽 logical signs. It was not for several days that it was $D$ appreciated that the patient had no memory for recent events and that gross confabulation wasn present. This state persisted for more than two weeks and remained unchanged despite protein withdrawal, enemata and chlortetracycline. Deathw then occurred following a massive gastro-intestinalo haemorrhage.

Portal-systemic encephalopathy in the alcoholic patient differs from that in the non-alcoholic in ? certain features. Mental changes more often include excitement and violence and the additional 
possibility of the clinical picture being clouded by the onset of alcoholic tremulousness, delirium tremens or Korsakow's psychosis, all of which are likely to occur in the course of unrelated illnesses, creates special diagnostic problems. Neurological features are identical with those in the nonalcoholic, save for the frequent absence of rigidity, hyper-reflexia and ankle clonus due to coincident peripheral neuritis.

Differential diagnosis of the alcoholic or malnutritional states may be easy in the well-developed case, but less characteristic examples, especially those arising under circumstances in which hepatic coma might be anticipated, may cause difficulty. Correct diagnosis is important, since the nutritious diet and sedation prescribed for the one group is so much at variance with the regime of minimal sedation and protein deprivation demanded by the other.

A detailed alcoholic and nutritional history, particularly relative to the period before mental disorder appeared, should be obtained. Possible precipitating factors of hepatic coma must be excluded while the presence and significance of associated neurological abnormalities is determined. The nature of the tremor and the relative prominence of mental excitement, convulsions, complex hallucinations, confabulation, ocular paralysis (all of which are relatively uncommon in portal - systemic encephalopathy) and fetor hepaticus must be considered.

Where doubt still remains the diagnosis may be clinched by finding E.E.G. changes of hepatic coma or observing the favourable response of patients with this condition to a trial of protein withdrawal and chlortetracycline.

\section{Subdural Haematoma}

A high incidence of trauma and increased bleeding tendencies expose the alcoholic with hepatic cirrhosis to the hazard of subdural haematoma. The injury may have been relatively light and frequently cannot be recalled. In the acute form loss of consciousness is usually preceded by headache, confusion, irritability and localizing signs, of which hemiparesis is the most common. Personality changes, intellectual deterioration, intermittent headache and localizing signs, which include evidence of an upper motor neurone lesion, papilloedema, or inequality of the pupils, should raise the possibility of chronic subdural haematoma in the susceptible subject.

Examination of the cerebrospinal fluid (which shows no abnormal routine findings in hepatic coma) for inconstant changes in pressure and protein level and E.E.G. records help differentiate subdural haematoma from the various types of hepatic coma. Nevertheless, many clinical features are common to both conditions and difficulty may arise, as is illustrated in the following case:

A 50-year-old tavern worker, a known alcoholic, was found lying unconscious in the road. Friends reported that during the previous day altered behaviour and incoherence of speech were evident. On examination he responded only to painful stimuli and had generalized hyperreflexia and extensor plantar reflexes. Fetor hepaticus, vascular spiders and hepato-splenomegaly were present. On protein withdrawal he became alert and orientated, exhibiting a transient non-specific tremor, but with persistent hyper-reflexia and a left-sided extensor plantar response. Soon afterwards he became drowsy and inattentive. Emergency burr holes revealed a large right temporo-parietal subdural haematoma; he made a satisfactory recovery following its evacuation.

\section{Hepato-Lenticular Degeneration}

Hepato-lenticular degeneration (Wilson's disease) is a condition in which deranged metabolism of copper results in disease of the central nervous system and hepatic cirrhosis. The salient psychiatric features are a progressive organic dementia -mild in juvenile cases - emotional lability and character changes expressed as behaviour disorders in children. The open-mouthed grin and drooling, alert eyes with corneal rings and disorders of movement, posture and speech are characteristic. Tremor, in late cases, has no 'flapping' quality and the neuro-psychiatric changes lack the fluctuations and relationship to dietary protein which characterize portal - systemic encephalopathy. Patients with this disease may also experience portal-systemic encephalopathy if the liver disease is sufficiently severe or the portal collateral circulation sufficiently great.

\section{Summary}

The occurrence of mental disorder in association with hepatic disease has been observed from antiquity and various psychiatric syndromes incident to liver disease can now be recognized. The concept of cerebral intoxication by nitrogenous substances derived from the intestine to account for a neuro-psychiatric syndrome (portal-systemic encephalopathy) provides a rational basis for effective therapy. This syndrome may occur as an acute or chronic organic reaction with an associated neurological disorder and E.E.G. abnormalities and may be modified by the concurrence of alcoholic and malnutritional syndromes. Functional reactions, which include depression in virus hepatitis and the post-hepatitis syndrome, may also complicate the chronic organic reaction. A progressive organic dementia characterizes hepatolenticular degeneration. 


\section{Acknowledgments}

We are grateful to Dr. Sheila Sherlock and Dr. Charles S. Davidson for allowing us to study patients under their care. We wish to thank the Medical Research Council for a personal grant to one of us (E.A.D.).

\section{BIBLIOGRAPHY}

ADAMS, R. D., and FOLEy, J. M. (1953), Res. Publ. Assn. Res. Nerv. Ment. Dis., 32, 198.

ANON., 'De Morbis Internis,' 27.

ATKINSON, M., BARNETT, E., SHERLOCK, S., and STEINER, R. E. (1955), Quart. F. Med., n.s. 24, 77 .

BAUMANN, E. D. (193I), fanus 35,153 and 185 .

BENHAMOU, J. P., HARTMANN, L., and FAUVERT, R. (I955), Presse medicale, 63, $145 \mathrm{I}$.

FINDLAY, G. M., and MARTIN, N. H. (1943), Lancet, i, 678.

FORD, J. C. (1943), Ibid., I, 675.

GALEN (A.D. 131-200), quoted by Baumann, E. D.

HIPPOCRATES (460-370 B.C). 'Epidemiorum,' 3: 'Hippocrates with an English Translation,' W. H. S. Jones, I, 219, Heinemann, London.

HIPPOCRATES (460-370 B.c). 'The Sacred Disease,' 18 : 'Hippocrates with an English Translation,' W. H. S. Jones, 2 177, Heinemann, London.
KIRK, E. (1936), Acta. med. Scand., 77, suppl. p. I.

LICHTMAN, S. S. (1953), 'Diseases of Liver, Gall Bladder and0̄ Bile Ducts,' r, 484, 3rd Ed., Klimpton, London.

LEIBOWITZ, S., and GORMAN, W. F. (1952), New Engl. $\not{y} . Z$ Med. 246, 932.

MAYER-GROSS, W., SLATER, E., and ROTH, M. (1954) @ 'Clinical Psychiatry,' p. 299. Cassell \& Co. Ltd., London.

MCDERMOTT, W. V., Jr., and ADAMS, R. D. (1954), f. clin Invest., 33, I.

PHILLIPS, G. B., SCHWARTZ, R., GABUZDA, G. J., Jr. DAVIDSON, C. S. (1952), New Engl. F. Med., 247, 239.

QUASTEL, J. H. (1932), Lancet, ii, 1417.

SOLOMON, P., and ARING, C. D. (1934), Amer. F. med. Sci., 188,805 .

SPENCE, J. C., and OGILVIE, A. G. (1927), Arch. Dis. Childh. $\stackrel{\mathbb{Q}}{\varrho}$ 2, $4 \mathrm{I}$.

SHERLOCK, S., SUMMERSKILL, W. H. J:, WHITE, L. P., ڤ) and PHEAR, E. A. (1954), Lancet, ii, 453.

SHERLOCK, S., and WALSHE, V. (1946), Lancet, ii, 482.

SUMMERSKILL, W.H. J., DAVIDSON, E.A., SHERLOCK,'S. and STEINER, R. E. (I956), Quart. $\mathscr{F}$. Med. n.s. 25, 245.

VAN CAULAERT, C., DEVILLER, C., and HALFF, (1932), C. R. Soc. Biol., Paris, III, 735.

VICTOR, M., and ADAMS, R. D. (1953), A. Res. Nerv. and Ment Dis. Proc., 32, 526.

VON JAUREGG, W. (1806); Wien Klin. Wochenschr., 9, 165. WOOLER, G. (1955), Personal communication.

ZILLIG, G. (1947), Nervenarzt, 18, 297.

\section{RUTHIN CASTLE, NORTH WALES}

A Clinic for the diagnosis and treatment of Internal Diseases (except Mental or Infectious Diseases). The Clinic is provided with a staff of doctors, technicians and nurses.

The surroundings are beautiful. The climate is mild. There is central heating throughout. The annual rainfall is 30.5 inches, that is, less than the average for England.

The Fees are inclusive and vary according to the room occupied.

For particulars apply to THE SECRETARY, Ruthin Castle, North Wales.

Telegrams: Cascle, Ruthin.

Telophone: Ruchin 66

Bibliography continued from page 485-Michael Atkinson, M.D. (Lond.), M.R.C.P.

AXELRAD B. J, CATES, J, E, JOHNSON, B, B., and LUETSCHER, J. A. (1955), Brit. med. F., i, I96.

BJORNEBOE, M., BRUN, C., and RAASCHOU, F. (1949), Arch. Int. Med., 83, 539 .

CHART, J. J., SHIPLEY, E. G. (1953), f. clin. Invest., 32, 560.

CHART, J. J., GORDON, E. S., HELMER, P., and LESHER, M. (I956), Ұ. clin. Invest., 35, 254.

DAVIDSON, C. S. (1955), F. Amer. med. Ass., 159, 1257.

EISENMENGER, W. J., BLONDHEIM, S., BONGIOVANNI, A. M., and KUNKEL, H. G. (1950), $\mathcal{f}$. clin. Invest., 29, 1491 .

FALOON, W. W., ECKHARDT, R. D., MURPHY, T. L. COOPER, A. M., and DAVIDSON, 'C. S. (1949), $\mathcal{f}$. clin. Invest., 28,583 .

GIGES, B., and KUNKEL, H. G. (1954), F. clin. Invest., 33, 257. GOODYER, A. V. N., RELMAN, A. S., LAWRASON, F. D., and EPSTEIN, F. H. (1950), ' F. clin. Invest., 29, 973.

HILTON, J. G. (1952), Am. F. Med., 12, 31 I.

HYATT, R. E., LAWRENCE, G. H., and SMITH, J. R. (1955), F. Lab. Clin. Med., 45, 274.

JONES, R. A., MCDONALD, G. O., and LAST, J. H. (1952), F. clin. Invest., $3 \mathrm{I}, 326$.

KLATSKIN, G., and YESNER, R. (1949), F. clin. Invest., 28, 723.

NELSON, W. P., and WELT, L. G. (1952), F. clin. Invest., 31, 392.

NELSON, W. P., ROSENBAUM, J. D., and STRAUSS, M. B. (1951), $\Im$. clin. Invest., 30, 738 .
PATEK, A. J., MANKIN, H., COLCHER, H., LOWELL, A. and EARLE, J. R. (1948), ' 7 . clin. Invest., 27, 135.

PHILLIPS, G. B. SCHWARTZ, R., GABUZDA, G. J., and DAVIDSON, C. S. (1952), New Engl. F. Med., 247, 239 .

PREEDY, J. R. K., and AITKEN, E. H. (1956), Ұ. clin. Invest., 35, 430.

PRENTICE, T. C., SIRI, W., and JOINER, E. E. (1952), $A m .0$ F. Med., 13, 668 .

RALLI, E. P., ROBSON, J. S., CLARKE, D., and HOAGLAND, C. L. (1945), . clin. Invest., 24, 316.

RATNOFF, O. D., and PATEK, A. J. (1942), Medicine, 21, 207. SCHOENBERGER, J. A., KROLL, G., SAKAMOTO, A., andN KARK, R. M. (1952), $¥$. Lab. clin. Med., 40, 94I.

SHERLOCK, S. (1955), 'Diseases of the Liver and Biliary System, $N$ Blackwell Scientific Publications, Oxford.

STARLING, E. H. (1896), f. Physiol., 19, 312.

STRUB, I. H., TALSO, P. J., and KIRSNER, J. B. (I955) Gastroenterology, 28, 163

TALSO, P. J., SPAFFORD, N., FERENZI, G., and JACKSON, H. O. (1956), Metabolism, 5, 58.

VOLWILER, W., GRINDLAY, J. H., and BOLLMAN, J. L. (1950), Gastroenterology, 14, 40.

WHITE, A. G., RUBIN, G., and LEITER, L. (195I), $尹$. clin. $\frac{T}{T}$ Invest., 31, 392. 